Kozyra Magdalena, Nowińska Martyna, Klas Jakub, Pytka Michalina, Lopuszańska Urszula. The latest research on risk factors and pathomechanisms of depression - review. Journal of Education, Health and Sport. 2020;10(11):50-60. eISSN 2391-8306. DOI http://dx.doi.org/10.12775/JEHS.2020.10.11.005

https://apcz.umk.pl/czasopisma/index.php/JEHS/article/view/JEHS.2020.10.11.005

https://zenodo.org/record/4264993

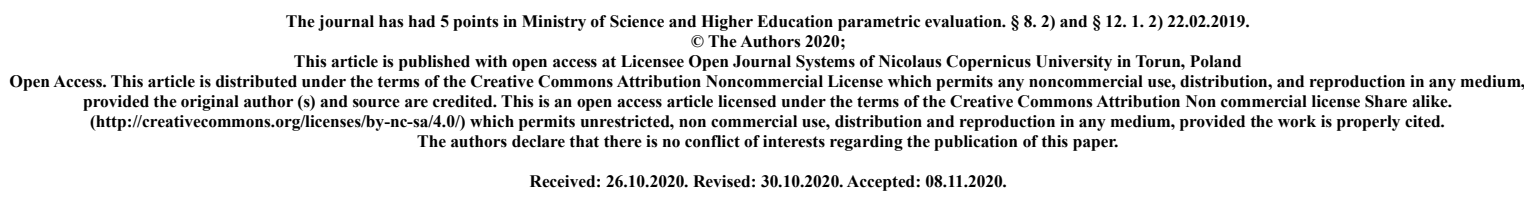

\title{
The latest research on risk factors and pathomechanisms of depression - review
}

\author{
Magdalena Kozyra $^{1}$, Martyna Nowińska ${ }^{1}$, Jakub Klas ${ }^{1}$, Michalina Pytka ${ }^{1}$, \\ Urszula Lopuszańska ${ }^{2}$
}

(1) Student Research Group of Applied Psychology, Medical University of Lublin

(2) Department of Applied Psychology, Medical University of Lublin

*Address for correspodence: Staffa 24, 20-454 Lublin, telephone number: 695562174, e-mail address: madzia.kozyra.1221@poczta.onet.pl

\section{ORCID ID and E-mail}

Magdalena Kozyra https://orcid.org/0000-0002-0260-4102

madzia.kozyra.1221@poczta.onet.pl

Martyna Nowińska https://orcid.org/0000-0002-8167-698X m.nowinska98@gmail.com Jakub Klas https://orcid.org/0000-0002-4795-1909 jakubklas99@gmail.com

Michalina Pytka https://orcid.org/0000-0002-4813-9357 Michalinapytka@gmail.com Urszula Lopuszańska https://orcid.org/0000-0001-6517-7577 urszulalopuszanska@umlub.pl

\begin{abstract}
Introduction: Depression is a mental disorder that is increasingly being diagnosed in middle and more developed countries (MDC). Symptoms of depression in patients with severe depressive disorder (MDD) include sadness, regret, negative thoughts, anxiety, and more.
\end{abstract}


The aim of the study: The aim of the study was to summarize the latest research (from 2020) on factors related to the occurrence of depression, as well as the current findings on depression (also those related to the COVID-19 pandemic).

Material and method: For this purpose, scientific search engines such as PubMed and Google Scholar were used.

Description of the state of knowledge: In 2020, apart from research on pathomechanisms and environmental factors, a large part of the research focused on the COVID-19 pandemic as a risk factor for the development of depression symptoms. Many studies from different parts of the world have confirmed that a pandemic can have a significant impact on the occurrence of depression.

Summary: There are many factors that can cause depression and it is important to keep them in mind both in everyday life and in clinical practice. Studies from various parts of the world have shown that the COVID-19 pandemic has exacerbated the experience of depressive symptoms, also in those who have not yet been diagnosed with MDD. The degree of severity of depressive symptoms depended on such factors as: financial situation, social isolation.

Key words: depression, SARS-CoV2, genetic, markers, inflammation, patomechanism 


\section{Introduction}

Every person experiences sadness, regret, despair and disappointment. Often people who have had painful life experiences behind them describe themselves as depressed. However, despite experiencing a depressed mood, they do not give up taking various actions in their life, and when something good happens, they can enjoy it. So feeling sad is not a disease. Clinical depression (also major depressive disorder - MDD) is usually more than just a painful emotional experience. It is a set of symptoms that last longer than the common feeling of depression, disrupting emotional and social life, cognitive processes, biological functions and causing changes in human behavior. [1]

Mood disorders are one of the most common mental disorders - their prevalence in the general population is around 15\%. The incidence in women is twice as high as in men [2].

Currently, the greatest spread of this disease takes place in the middle- and MDC countries [4]. Chronic depression ends in about $15 \%$ of cases suicide [3]. Symptoms of the disease include: increased feeling sadness and anxiety, low mood, loss of interest pleasures and decreased appetite [4]. As symptoms are also indicated changes in body weight and sleep pattern, as well as concentration disorders and reduced cognitive abilities [3].

Currently, depressive disorders are considered a group of diseases so frequent that they constitute a serious health, social and economic problem. People experiencing depression often lose their ability to function in everyday life and they start to have problems at work. Untreated depression can lead to a deterioration in quality of life and even disability [5, 6]. As mentioned earlier, untreated depression increases the risk of suicide and committed suicide. [7].

Another important factor related to depression is the fact that up to $40 \%$ of patients worldwide do not respond adequately to antidepressants. [8].

Due to the growing incidence of depression in society, it is not the diagnosis itself that is of great clinical importance, but the treatment of depressive disorders in the first place. The main tasks of treating depression include: balancing the mood, reduce anxiety, improve the patient's functioning, regain self-confidence, return to pre-sickness social, professional and family roles, etc.

There are numerous therapeutic measures allowing to control symptoms of depression however, the most important role is played by pharmacotherapy (first and second generation antidepressants), usually administered orally, but also possible to be administered in the form of an intravenous drip in stationary conditions. The advantages of pharmacotherapy are relatively low costs, high safety and ease of use [9].

In treatment, various types of pharmacological agents are most often used for this purpose, such as: selective serotonin reuptake inhibitors (SSRIs) and tricyclic antidepressants (TCAs) [10, 11] supported by psychotherapy [12]. Limited possibilities and methods of treating depression are observed [13], therefore at present, there is a growing interest in alternative forms (in relation to pharmacotherapy) of treatment of this disease [14].

Depression is a multi-faceted disease that affects significantly, on the quality of life of the individual. It might be associated with survived trauma, disease (e.g. cancer) or induced other factors, including socioeconomic. Regardless of the cause of depression, treatment is carried out according to standard procedures, based on pharmacotherapy and psychotherapy [15]. 
However, the ineffectiveness of standard interventions has been demonstrated in many cases, therefore a modern treatment approach is needed [16].

\section{Materials, methods and aim}

A literature review was made using databases such as PubMed or Google Scholar. When selecting the articles, we searched for the latest, published in 2020 articles with the latest research on depression.

3. Markers of depressive disorders:

So far, in the world of science, we have encountered difficulties in diagnosing depressive disorders in patients. Recently, more and more markers have been shown that could serve as important factors in the diagnosis of MDD.

The levels of neurotoxic metabolites, which include 3-hydroxykynurein and quinolinic acid, were significantly increased in patients with MDD. Their number was reduced by exercise and electroconvulsive therapy. Their amount is increased by interferon, which in turn reduced the level of the neuroprotective metabolite - kynureic acid and tryptophan. The tryptophan-kynurein pathway may be involved in the pathomechanism of depression by inducing an inflammatory response [17]. Anti-inflammatory treatments have been shown to reduce symptoms of depression.

Inflammation markers are very important in the diagnosis of MDD. HPA-axis hyperactivation reduces mood and the development of somatic symptoms, but not cognitiveaffective symptoms. Elevated cortisol and CRP are reliable biomarkers of somatic symptoms, but not general symptoms of depression. Increased levels of hair cortisol and plasma CRP were associated with more persistent symptoms of depression over a 14-year period in a large sample of adults [18].

Interleukin 6 is known for its pro-inflammatory properties. Its level is significantly elevated in people with depression. IL-6 levels have been associated with MDD subtypes, clinical features, therapeutic responses, and prognosis. Restoring IL-6 levels to normal is key to treating depression, which include inflammation. Reducing the high level of proinflammatory IL-6 is possible thanks to: probiotics, exercise, phototherapy, electroconvulsive therapy and antidepressants [19]. 
Post-inflammatory changes following peripheral immune challenge lead to a decrease in the level of glutamate in the brain, which influences the occurrence of depressive behaviors [20].

\section{Impact of environmental factors on MDD:}

In 2020, many studies focused on the influence of the gut microbiota on the occurrence of depressive symptoms. The beneficial effect of vitamin B11 and B12 supplementation has been shown to improve mood. However, they did not significantly reduce anxiety [21]. The dietary recommendations promoted the consumption of fish, fiber, olive oil and low-fat dairy products. It was recommended to avoid high-fat dairy products and processed red meat [22]. The Mediterranean diet has been proven to alleviate the symptoms of depression. A proper diet reduces the duration of depressive episodes and increases the number of bacteria with anti-inflammatory properties, which include Firmicutes, while Lactobacillus and Bifidobacterium have a positive effect on mood changes. The amount of bacteria of the aforementioned types is reduced in MDD patients. On the other hand, the number of bacteria with pro-inflammatory properties increases - they include, among others - Bacteroidetes [21].

The experiment on mice confirmed the above research. The animals were recipients of microbiome transplants from sick and healthy donors. The microflora from donors of MDD patients caused increased inflammation, anhedonia and anxiety-like behaviors compared to the group that received FMT from healthy volunteers [21].

Another factor significantly influencing the development of MDD is exposure to light at night (LAN). It also affects the disturbance of the circadian rhythm, which is correlated with the intestinal microbiota. The neural pathway of light begins in the cells of the retina, where melanopsin is expressed. It runs to the dorsal perihabenular nucleus (dpHb) and on to nucleus accumbens (NAc). This pathway preferentially carries light signals at night, mediating depressive-type behaviors caused by LAN [23].

\section{COVID-19 and the risk of increased depression incidence}

Due to the ongoing COVID-19 pandemic causing acute respiratory distress COVID-19, there is a risk of increased incidence of depression. This section presents a review of the literature from the current year regarding the impact of the ongoing pandemic on the need to diagnose and hospitalize more depressed patients than in previous years [24]. 
One of the most frequent research studies was to examine the percentage of people at risk of developing depression and the percentage of people experiencing anxiety related to the epidemiological situation at that time. Such studies were carried out, for example, in India [24] or Bangladesh [25], the United States [26] or Germany [27] in any group of people. Studies on the increase in anxiety and depressive symptoms in patients or depending on the degree of quarantine were also published.

In a study from India [24], respondents were asked to fill in a Google Form containing, inter alia, The Depression, Anxiety and Stress Scale (Lovibond, Lovibond 1995) or the Family Wealth Scale (Currie et al. 2008) to compare the financial situation to the mental state of the respondents. The final data included 390 people (108 men and 280 women, and 2 people claiming to be non-binary). For the analysis by professional group, students, teachers, researchers, mental health professionals, healthcare professionals and corporate employees were included, as there was a sufficient number of respondents in these groups. They found that respondents who did not have a stable financial situation (showed the lowest level of poverty) reported moderate levels of stress, severe anxiety and moderate depressive states, while those who did not have a stable situation regarding the availability of goods reported mild stress, moderate anxiety and moderate depression. Even people with a stable financial and food situation, according to the questionnaire, showed mild stress, moderate anxiety and mild depressive states. By profession, teachers, mental health professionals, and corporate employees generally showed no symptoms of depression, while healthcare professionals and researchers showed mild depressive stages, while students showed moderate depressive stages. As for the differences between the sexes in terms of stress, anxiety and depression, no significant differences in the mental condition of the respondents were noticed. It was found that the respondents showed mildly depressive stages on average, while the level of anxiety was moderate. The results of the research indicate that schoolchildren, students and health care workers require special attention due to their greater mental suffering, which was confirmed in the earlier studies mentioned in the article [28] [29] [30].

In a study conducted on students from Bangladesh [25] in which 464 respondents were examined, after completing the standardized questionnaire, it turned out that the students experienced increased values of depression and anxiety. About $15 \%$ of the students, according to the survey results, showed moderate depression, while $18.1 \%$ experienced severe anxiety. Binary logistic regression suggests that older students tend to develop into more severe stages of depression. 392 participants (82.4\% of the respondents) experienced any depressive symptoms, while $87.7 \%$ of the respondents experienced anxiety. Comparing previous studies, a significant increase in the phenomenon can be noticed. For example, a 2015 study among medical students showed that over $50 \%$ of medical university students suffer from depression (54.3\%) and anxiety (64.8\%) [31]. Another study conducted on students excluding first-year students, complementing the previous work, showed that the incidence of depression and anxiety was $52.2 \%$ and $58.1 \%$, respectively [32]. This study clearly showed a dynamic increase in depressive episodes and the experience of anxiety in connection with the prevailing epidemiological situation. In addition, it was shown that men (67.35\%) had greater symptoms of depression than women (32.65\%). Depression also affected less active students, physically inactive (62.24\%) and those who consider themselves to be in as much in terms of academic activity (76.78\%). Moreover, students living with their families (96.93\%) and in cities (65.05\%) showed more depressive symptoms. The students who gave such answers sometimes had more than 1.8 - 3 times higher risk of developing depression compared to the respondents giving opposite answers in the survey. 
The American study [26] compared the results of the depression questionnaire completed by respondents both before and after the pandemic, and made an attempt to find the cause of this phenomenon. The questionnaire was completed by 1,441 respondents from the COVID19 pandemic period and 5,065 pre-pandemic respondents. The study found that the incidence of depression symptoms in the U.S. increased more than 3-fold during the COVID-19 pandemic, from $8.5 \%$ before COVID-19 to $27.8 \%$ during COVID-19. It showed a reduced percentage of people without depression symptoms and a greater percentage of respondents with more symptoms during COVID-19 than before COVID-19. They also found that lowerincome groups were more likely to develop symptoms of depression than higher-income groups, and having savings of less than \$ 5,000 was associated with a 1.5-fold increase in the likelihood of developing symptoms of depression, a 50\% higher risk. Therefore, the current epidemic has adversely affected the worst-off citizens, whose unstable financial situation is most susceptible to dynamic changes in the labor market.

In Germany [27], in a study of a group of over a dozen thousand people, significantly increased symptoms were also noticed in the following categories: generalized anxiety (44.9\%), depression (14.3\%), mental distress (65.2\%) and fear related to COVID- 19 (59\%). Women and younger people reported greater psychological burden. Confidence in government efforts to tackle COVID-19 and an objective level of information on COVID-19 are negatively related to the mental health strain. A greater risk, however, is the subjective level of COVID-19 information, as it is positively associated with increased fear of COVID19. As in the study in Bangladesh, a significant upward trend in the occurrence of depressive states was shown. The frequency of at least mild symptoms of generalized anxiety disorder was $44.9 \%$, while $16.8 \%$ of the current sample had moderate generalized anxiety symptoms. The results of the latter category are strongly increased compared to previously published studies in Germany with $6.0 \%$ and $5.9 \%$, respectively, of the prevalence of moderate anxiety symptoms [33] [34].

The increasing tendency towards depressive behaviors also applies to convalescents after contracting COVID-19 [35]. In one study, 402 patients who were COVID-19 survivors (265 men, mean age 57.8, age range 18 to 87) were interviewed for psychiatric symptoms. COVID-19 survivors showed a high incidence of emerging psychiatric sequelae, with $55 \%$ of the sample tested having a pathological outcome for at least one disorder. Survivors are expected to have a higher-than-average incidence of PTSD, major depression, and anxiety, all non-infectious, high-burden conditions associated with years of life with disability. Attempts were made to find correlations between the presence of markers of inflammation and the value of oxygen saturation in the body with the frequency of depressive symptoms (as in hospitalized patients the values of inflammatory markers and oxygen saturation were successively higher and lower compared to patients treated at home), but such a correlation was not demonstrated.

It was also checked to what extent undergoing quarantine revealed depressive symptoms [36]. The study sample of 1,160 subjects consisted of three groups: people quarantined in the affected area, people quarantined from intact areas, and people not quarantined. The Depression Scale of the Epidemiological Research Center (CES-D-20) and the Goldberg Depression and Anxiety Scale (GAD-7) were used as measures of depression and anxiety, respectively. Probable depression and anxiety were reported by $26.47 \%$ and $70.78 \%$ of all respondents, respectively. Adjusted for demographic and social variables, quarantined respondents reported a greater likelihood of showing symptoms of depression and anxiety than those who were not quarantined, indicating a negative mental health impact of forced 
isolation. In addition, respondents living in communities where COVID-19 screening was required were less likely to report symptoms of depression and anxiety, possibly due to a shorter life of uncertainty about their own health.

Summarizing, the results of the latest scientific research pose a great challenge to the state of public health in countries around the world, especially in countries with a large percentage of people with financial instability. As you can see, this problem affects both people who have experienced COVID-19 behavior, have been quarantined, and people whose epidemiological restrictions have affected the lives of every citizen. It is therefore necessary to provide psychological medical assistance in every social and professional group, which is a major challenge for governments at all latitudes [24] [25] [26] [27].

\section{Summary}

A number of this year's studies significantly contributed to the understanding of the pathomechanisms and risk factors for the development of depression. Still new research gives us a broader understanding of the subject, and still new discoveries show that there is still much to be researched. Therefore, it is worth remembering that a lot of things still remain unexplored and await new research.

It is worth emphasizing once again significant research from this year, such as the precise determination of the pathomechanism of depression induced by night exposure to light (LAN). The path of light stimuli conduction has been carefully marked and it has been confirmed that it may cause depression [23].

Subsequent studies again highlighted the important effect of diet on depression. It turns out that a healthy lifestyle and a recommended diet rich in fish, fiber and low-fat dairy products significantly reduces depression (but without affecting anxiety) [22] and may also affect the number of anti-inflammatory bacterial flora. Similarly, the Mediterranean diet alleviates symptoms of depression [21].

As with bacterial flora that are anti-inflammatory, anti-inflammatory treatments can reduce symptoms of depression. Interferon for this may be responsible for the reduction of the amount of 3-hydroxykynurein and quinolinic acid, which elevated levels are observed in MDD patients [17]. Given the above, it should come as no surprise that pro-inflammatory IL6 is elevated in people with MDD [19].

When talking about the latest research related to depression from 2020, it is impossible not to mention those that analyze a new predisposing factor for depression, which is the global virus pandemic SARS- CoV2.

A number of studies have investigated whether the pandemic might have had an impact on feelings of danger, anxiety and depression. Similar studies were conducted on different continents among many citizens of countries such as India, the United States and Germany.

American researchers found a 3-fold increase in the incidence of depression in the respondents during the pandemic compared to the respondents before the pandemic [26]. In turn, Indian scientists estimated that the most vulnerable group of people who may develop depression caused by the COVID-19 pandemic are health care workers, scientists and students 
[24]. Again, as if looking only at a group of students, a study of Bangladeshi students, among other things, proved that recent years students are the most vulnerable [25].

It is worth noting that in patients, after recovalence after contracting COVID-19, an increased frequency of psychiatric symptoms and a tendency to disorders such as PTSD, depression or anxiety was found [35]. Moreover, the quarantine itself was able to increase the level of anxiety and depression among the respondents [36]. This was probably due to uncertainty about a possible infection. Which can be confirmed by the fact that among the respondents who were screened for the presence of SARS-CoV2, symptoms of anxiety and depression were less frequent.

\section{References:}

[1] Sprawka K, Wysokiński A, Orzechowska A, Talarowska-Bogusz M, Typel D, Gruszczyński W (2008) Zaburzenia depresyjne i lękowe w okresie klimakterium. Psychiatr 5:99-104.

[2] Brown T., Melchior L., Huba G. Level of burden among women diagnosed with severe mental illness and substance abuse. J. Psychoactive Drugs 1999; 31: 31-41.

[3] 2. Ross BM. $\omega-3$ fatty acid deficiency in major depressive disorder is caused by the interaction between diet and genetically determined abnormality in phospholipid metabolism. Med Hypothes 2007; 68: 515-524.

[4] Bujnowska-Fedak M, Grata-Borkowska U, Sapilak B. Otępienie i depresja u pacjentów w podeszłym wieku w Praktyce Lekarza Rodzinnego. Fam Med Prim Care Rev 2012; 14(3): 349-353.

[5] Ustun TB, Ayuso-Mateos JL, Chatterji S, Mathers C, Murray CJ. Global burden of depressive disorders in the year 2000. Brit. J. Psychiatry 2004; 184: 386-392.

[6] Judd LL, Paulus MP, Wells KB, Rapaport MH. Socioeconomic burden of subsyndromal depressive symptoms and major depression in a sample of the general population. Am. J. Psychiatry 1996; 153: 1411-1417.

[7] Pużyński S. Depresje i samobójstwa. W: Pużyński S. red. Depresje i zaburzenia afektywne. Warszawa: Wydawnictwo Lekarskie PZWL; 2005, s. 98-107.

[8] Holtzheimer PE, Mayberg HS. Stuck in a rut: rethinking depression and its treatment. Trends Neurosci. 2011;34:1-9.

[9] Zyss T. Nowe techniki stymulacji elektrycznej i magnetycznej $\mathrm{w}$ terapii depresji porównanie z elektrowstrząsami i farmakoterapią. Psychiatria Polska 2010, tom XLIV, numer 6, strony 853-869.

[10] Perzyński A. Poziom funkcjonowania i rozpoznania stawiane przez psychiatrów u pacjentów kierowanych do poradni zdrowia psychicznego przez lekarzy rodzinnych. Fam Med Prim Care Rev 2013; 15(3): 368-369.

[11] Ross BM. $\omega-3$ fatty acid deficiency in major depressive disorder is caused by the interaction between diet and genetically determined abnormality in phospholipid metabolism. Med Hypothes 2007; 68: 515-524. 
[12] Lakhan SE, Vieira KF. Nutritional therapies for mental disorders. Nutr J 2008; 7: 2. [13] Harbottle L, Schonfelder N. Nutrition and depression: a review of the evidence. J Ment Health 2008; 17(6): 576-587.

[14] America A, Milling LS. The efficacy of vitamins for reducing or preventing depression symptoms in healthy individuals: natural remedy or placebo? J Behav Med 2008; 31: 157167.

[15] Lakhan SE, Vieira KF. Nutritional therapies for mental disorders. Nutr J 2008; 7: 2.

[16] Roberts SH, Bedson E, Hughes DA, et al. Folate Augmentation of Treatment Evaluation for Depression (FolATED): protocol of a randomized controlled trial. BMC Psychiatry 2007; 7: 65.

[17]Pu J, Liu Y, Zhang H, Tian L, Gui S, Yu Y, Chen X, Chen Y, Yang L, Ran Y, Zhong X, Xu S, Song X, Liu L, Zheng P, Wang H, Xie P. An integrated meta-analysis of peripheral blood metabolites and biological functions in major depressive disorder. Mol Psychiatry. 2020 Jan 20. doi: 10.1038/s41380-020-0645-4. Epub ahead of print. PMID: 31959849.

[18]Iob E, Kirschbaum C, Steptoe A. Persistent depressive symptoms, HPA-axis hyperactivity, and inflammation: the role of cognitive-affective and somatic symptoms. Mol Psychiatry. 2020 May;25(5):1130-1140. doi: 10.1038/s41380-019-0501-6. Epub 2019 Aug 21. PMID: 31435001; PMCID: PMC7192852.

[19]Ting EY, Yang AC, Tsai SJ. Role of Interleukin-6 in Depressive Disorder. Int J Mol Sci. 2020 Mar 22;21(6):2194. doi: 10.3390/ijms21062194. PMID: 32235786; PMCID: PMC7139933.

[20] Chan SY, Probert F, Radford-Smith DE, Hebert JC, Claridge TDW, Anthony DC, Burnet PWJ. Post-inflammatory behavioural despair in male mice is associated with reduced cortical glutamate-glutamine ratios, and circulating lipid and energy metabolites. Sci Rep. 2020 Oct 8;10(1):16857. doi: 10.1038/s41598-020-74008-w. PMID: 33033375; PMCID: PMC7545201.

[21]Bastiaanssen TFS, Cussotto S, Claesson MJ, Clarke G, Dinan TG, Cryan JF. Gutted! Unraveling the Role of the Microbiome in Major Depressive Disorder. Harv Rev Psychiatry. 2020 Jan/Feb;28(1):26-39. doi: 10.1097/HRP.0000000000000243. PMID: 31913980; PMCID: PMC7012351.

[22]Nicolaou M, Colpo M, Vermeulen E, Elstgeest LEM, Cabout M, Gibson-Smith D, Knuppel A, Sini G, Schoenaker DAJM, Mishra GD, Lok A, Penninx BWJH, Bandinelli S, Brunner EJ, Zwinderman AH, Brouwer IA, Visser M. Association of a priori dietary patterns with depressive symptoms: a harmonised meta-analysis of observational studies. Psychol Med. 2020 Aug;50(11):1872-1883. doi: 10.1017/S0033291719001958. Epub 2019 Aug 14. PMID: 31409435; PMCID: PMC7477372.

[23]An K, Zhao H, Miao Y, Xu Q, Li YF, Ma YQ, Shi YM, Shen JW, Meng JJ, Yao YG, Zhang Z, Chen JT, Bao J, Zhang M, Xue T. A circadian rhythm-gated subcortical pathway for nighttime-light-induced depressive-like behaviors in mice. Nat Neurosci. 2020 Jul;23(7):869880. doi: 10.1038/s41593-020-0640-8. Epub 2020 Jun 1. PMID: 32483349.

[24] Rehman, U., Shahnawaz, M. G., Khan, N. H., Kharshiing, K. D., Khursheed, M., Gupta, K., . . . Uniyal, R. (2020). Depression, Anxiety and Stress Among Indians in Times of Covid19 Lockdown. Community Mental Health Journal. doi:10.1007/s10597-020-00664-x 
[25] Islam, M. A., Barna, S. D., Raihan, H., Khan, M. N., \& Hossain, M. T. (2020). Depression and anxiety among university students during the COVID-19 pandemic in Bangladesh: A web-based cross-sectional survey. Plos One, 15(8). doi:10.1371/journal.pone.0238162

[26] Ettman, C. K., Abdalla, S. M., Cohen, G. H., Sampson, L., Vivier, P. M., \& Galea, S. (2020). Prevalence of Depression Symptoms in US Adults Before and During the COVID-19 Pandemic. JAMA Network Open, 3(9). doi:10.1001/jamanetworkopen.2020.19686

[27] Bäuerle, A., Teufel, M., Musche, V., Weismüller, B., Kohler, H., Hetkamp, M., . . Skoda, E. (2020). Increased generalized anxiety, depression and distress during the COVID-19 pandemic: A cross-sectional study in Germany. Journal of Public Health. doi:10.1093/pubmed/fdaa106

[28] Sahu, P. (2020). Closure of Universities Due to Coronavirus Disease 2019 (COVID-19): Impact on Education and Mental Health of Students and Academic Staff. Cureus. doi:10.7759/cureus.7541

[29] Cao, W., Fang, Z., Hou, G., Han, M., Xu, X., Dong, J., \& Zheng, J. (2020). The psychological impact of the COVID-19 epidemic on college students in China. Psychiatry Research, 287, 112934. doi:10.1016/j.psychres.2020.112934

[30] Law, T. (2020, April 17). Medical workers fighting COVID-19 are facing a mental health crisis. https://time.com/5817435/covid-19-mental-health-coronavirus/

[31] Alim S, Rabbani M, Karim E, Mullick M, Al Mamun A, Khan M. Assessment of depression, anxiety and stress among first year MBBS students of a public medical college, Bangladesh. Bangladesh Journal of Psychiatry. 2015;29(1):23-9.

[32] Mamun MA, Hossain MS, Griffiths MD. Mental health problems and associated predictors among Bangladeshi students. International Journal of Mental Health and Addiction. 2019.

[33] Löwe, B., Decker, O., Müller, S., Brähler, E., Schellberg, D., Herzog, W., \& Herzberg, P. Y. (2008). Validation and Standardization of the Generalized Anxiety Disorder Screener (GAD-7) in the General Population. Medical Care, 46(3), 266-274. doi:10.1097/mlr.0b013e318160d093

[34] Hinz, A., Klein, A. M., Brähler, E., Glaesmer, H., Luck, T., Riedel-Heller, S. G., . . . Hilbert, A. (2017). Psychometric evaluation of the Generalized Anxiety Disorder Screener GAD-7, based on a large German general population sample. Journal of Affective Disorders, 210, 338-344. doi:10.1016/j.jad.2016.12.012

[35] Mazza, M. G., Lorenzo, R. D., Conte, C., Poletti, S., Vai, B., Bollettini, I., . . Benedetti, F. (2020). Anxiety and depression in COVID-19 survivors: Role of inflammatory and clinical predictors. Brain, Behavior, and Immunity, 89, 594-600. doi:10.1016/j.bbi.2020.07.037

[36] Tang, F., Liang, J., Zhang, H., Kelifa, M. M., He, Q., \& Wang, P. (2020). COVID-19 related depression and anxiety among quarantined respondents. Psychology \& Health, 1-15. doi:10.1080/08870446.2020.1782410 